\title{
Digital technology models in modern school (FL learning experience)
}

\author{
Ludmila Stolyarchuk, Elena Meshcheryakova, and Marina Zheltukhina* \\ Volgograd State Socio-Pedagogical University, Volgograd, Russia
}

\begin{abstract}
The present paper describes digital technology models in modern schools within distance education as foreign language learning experience. The given description is supported by the survey results among schoolchildren as FL learners in Volgograd. It was conducted in MarchApril 2020 and showed that most schoolchildren (77\%) were not ready for forced distance learning, introduced in connection with the Covid-19 spread. The experiment made it possible to apply digital technology models: "Single Media" presents pedagogical guidance for schoolchildren at low level of readiness, "Multimedia" gives pedagogical support for schoolchildren at medium level of readiness, and "Hypermedia" provides pedagogical support for schoolchildren at high level of readiness. These models give schoolchildren learning foreign languages the fastest adaptation and personal growth via digital learning.
\end{abstract}

\section{Introduction}

Humanity around the world in 2020 found itself in an unforeseen life situation of selfisolation caused by the Covid-19 pandemic, which seriously affected changes in education, which in an unprecedentedly short time, at an accelerated pace was forced to make the transition to distance learning for schoolchildren in the global world and Russia. The transition to a distance learning format made it possible to maintain the continuity of the educational process in schools during the academic year 2019-2020; the state timely fixed the legal status of distance education through amendments to the law "On Education in the Russian Federation" (Art. 16) [9].

In the current situation of active development of information society, the search for the most optimal theoretical models of digital technologies in a modern school, which allow increasing the level and efficiency of the renewing system of domestic education, aimed at improving the global system of distance education, corresponding to the dynamic, innovative technologies in educational practice, is becoming increasingly important $[10,14,16]$. The reliance of distance learning on digital technologies allows flexible responses to emerging societal and individual needs and demands of learners.

The analysis of world experience in the development of digital technology models in the modern school in a distance format shows that these models accumulate the accumulated baggage of audio-visual, programmed, distance, Internet-based learning tools at different

\footnotetext{
*Corresponding author: zzmr@mail.ru
} 
levels of education. In the modern world, the development of digital technology models in schools is due to the increasing number and quality of a variety of software products used for various educational purposes, the use of interactive video, teleconferencing, satellite television in educational activities; international integration into a piece of single information and educational space.

Researchers Verduin, J.R. Clark, T.A. interpret distance learning as learning at a distance, open, accessible to all, regardless of the level of education, geographical location, through various means and channels of communication [21]. Moore M.G. \& Thompson M.M. point out the importance of creating technological educational programs through video or audio recordings, cable and satellite TV, video conferencing, etc. At the same time, their dominant purpose is fixed in improving the quality of the educational process, personal growth of students, their attitudes, and achievements [19]. Garrison, D. R. \& Baynton, M., supporting and developing the ideas of Moore M.G., in distance learning focus on the organization of educational process with the help of information and telecommunication technologies, Internet tools, which should contribute to the accumulation of experience by learners based on real-time dialogue, support human and technical resources, increase the independence of students, expand their choices [15, pp. 3-15]. In line with the development of the idea of independence and the possibility of learners' choice, Soldeway D. explores the possibilities of organizing the educational process through information and telecommunication technologies, Internet tools, united in a consortium - a group of institutions or distance education programs that learners can choose for independent planning and organization of their educational routes in a distance education environment [14].

Domestic scientists such as V.A. Kuklev, O.P. Okolelov, V.I. Snegurova, A.V. Khutorskoy et al. investigate different models of digital technologies in modern schools for distance learning as a pedagogical educational system, the learning process of which is organized based on information and telecommunication technologies, Internet facilities [2, $3,6,10,11]$. Prospects for distance learning of foreign languages based on computer telecommunications are studied in the works of M.Y. Gorbukha, O.S. Tarasenko, and L.V. Burenko [1,7].

\section{Methodology}

In this study, we used digital technology models for distance learning in secondary schools as a methodological basis, proposed by A.V. Hutorsky [3], which synthesized the ideas of foreign and domestic researchers on open and accessible education for all, improving the quality of the educational process, contributing to the personal growth of students and their achievements, professional development, increasing independence, and expanding their choices based on dialogic interaction of students and teachers, mutual enrichment of educational information web-materials through the Internet [13]. Distance learning models differ in didactic distance content of the educational process.

The School-Internet digital technology model of distance learning aims to provide learners with new information from a teacher using Internet sources with pedagogical guidance for learners (low-readiness). Thanks to the teacher and the Internet, the visibility of this group of learners is enhanced in situations of spatial separation of teacher and learners (in this case, due to pandemic) or other reasons (inability of learners to travel due to temporary or permanent mobility restrictions, urgent move with parents, various extreme and unforeseen life circumstances). The format of online learning for all, despite the distance between the teacher and students, makes it possible to continue the educational process as a continuous, as the student with his "face-to-face" teacher interacts remotely, exchanging important information for the student and teacher; in the absence of video or audio using text chats based on online platforms: Skype, WhatsApp, Viber, Zoom, 
The School-Internet-School model is designed for learners (intermediate level of readiness) and interaction with teachers on the Internet in video lessons, video conferencing to organize discussions, debates, and disputes, allowing communication in remote access, participation in distance learning projects, scientific and practical conferences and other school activities. It is characterized by being organized but not systematic, providing an opportunity to discuss important school issues of recent decades, both globally, regionally, and locally within the school. The class can consist of full-time and distance learners; classes can be held remotely with students from the same school and with remote learners from different schools from other cities.

Another model of digital technology, "student-Internet-teacher", we also consider appropriate for students (middle level of readiness), as a type of distance learning, proceeding not only from the interests of the school but, above all, from the interests of the learner. Teachers continuously or episodically interact remotely with the student in the formats of online platforms: Skype, WhatsApp, Viber, etc., providing pedagogical support in situations when the student asks for advice, recommendations. Targeting the interaction sessions (at the student's request) and the remote teacher contributes to the quality of remote interaction content.

The model of digital technologies "Learner - Internet - Center" and "Learner - Internet ... (several centers, several teachers)" - for learners (high level of readiness), when each learner is ready to find the most convenient ways of knowledge acquisition for him/herself. As defined by A.V. Khutorsky, this model is a means of individualization of learning, aimed at finding additional opportunities for the disclosure of their creative potential, implementation of individual educational needs [11]. A change in the place and role of the main educational components of traditional education: goals, content, forms, and criteria for learning assessment have been noted. The student gets a unique opportunity to study not only in one full-time or distance school but also in several schools at once. This ensures independent planning, allocation of time and space for education, selection of a suitable educational institution and teachers. The coordinating role is played by parents or teachermentor, helping the student build an individual educational trajectory, taking into account their individual characteristics and educational goals. The educational content is filled, characterized by an adequate degree of distance, allowing to obtain the expected results. Students complete independent assignments via mobile devices and work with teachers to select the most convenient online platforms for organizing and conducting interactive lessons with the class.

\section{Results}

Surveys of school students of MOU "Lyceum No. 5 named after Yuri A.Gagarin", MOU "Gymnasia No. 1, 3 of the Central district of Volgograd", MOU "School No. 10, 19, 81, 83, 84 of the Central district of Volgograd", MOU "School No. 5, 32, 35, 73, 92 of Krasnooktyabrsky district of Volgograd", MOU "School No. 3, 17, 86 Traktorozavodsky district of Volgograd" conducted in (March-April-May) 2020 by the future teachers, during the period of pedagogical practice, under the guidance of the authors of this article using the questionnaire "My readiness for distance learning". And also, due to cooperation with teachers of English and German of comprehensive schools and joint analysis of video recordings of video lessons conducted by teachers of English, German (number of students present (and photo on the screen or real presence), their activity at the lesson, interest to lessons, quality of completed tasks)), analysis of conversations with students and their parents, the levels of readiness and attitude of school students to forced distance learning, introduced in connection with the spread of Covid-19 were identified. 
$78 \%$ of students who switched to online learning because of the pandemic were in favor of face-to-face learning and expressed dissatisfaction with the distance learning format because of the increased amount of homework. Pupils noted that they did not have time to do their homework on the textbook, not only during the recommended time but also during the whole day. $57 \%$ pointed out the difficulty of understanding and memorizing new material "remotely", without "live" explanations and pedagogical support from the teacher, and emphasized the greater fatigue compared to regular lessons. $48 \%$ of the respondents stated the importance of "live communication" with their classmates, which they lacked after the remote learning format introduced in the spring of 2020. Difficulties in the independent organization of their learning and leisure time were pointed out by $39 \%$ of schoolchildren (average level of readiness), $21 \%$ found that they could not organize it without supervision at all, $17 \%$ perceived distance learning as a vacation (schoolchildren of low readiness).

$29 \%$ of the surveyed pupils referred themselves to the supporters of partial distance learning. Still, on the condition that all pupils will have computers, Internet access, and everything will work properly, as in the current situation there were a lot of problems. $18 \%$ of pupils highlighted the disadvantages of full-time education - the inability to learn at their own pace. Only $23 \%$ of schoolchildren turned out to be ready for independent planning of studies, home affairs, recreation and entertainment, organization of their day (high level of readiness).

The obtained data served as a basis for us to apply digital technologies in a modern school following the low, medium, and high schoolchildren's readiness that we have identified based on the selected theoretical models.

When implementing the model of digital technologies of distance learning "SchoolInternet", for students (low-readiness level) we used digital technology "Single media", i.e., we used one of the means of learning and one channel of information transfer: correspondence, checking the completed tasks (on independent listening to video lessons "Asking and giving directions" - to repeat prepositions of place and direction, places in the city, activating skills of applying lexical units in oral speech, describing the way or questions on how to go; for mastering new words, solving problem situations, etc.) [17; 18]. The lack of simultaneous two-way communication transformed this technology of distance learning into traditional distance learning. Case technology (a special set of cases) was used for the assignments for independent study topics. Pedagogical supervision of pupils was exercised during knowledge control by a teacher. For this group of students, we used the platform study-languages-online.com to repeat the English alphabet with voiceover, learning and consolidating words, divided by topics (numbers from 1 to 10,15 to 20 and 10 to 100 , colors, fruits, vegetables, family, professions, school supplies, etc.) with repetition tasks following the speaker, with exercises to consolidate the material and master grammar. Teremoc.ru was used as learning games to develop memory and test the knowledge gained from the studylanguages-online.com platform.

When implementing the digital technology model "School-Internet-School" for students (medium level of readiness), we used the digital technology "Multimedia" on platforms: Skype, WhatsApp, Zoom, TrueConf, Discord, EDU (VGSPU platform), etc. Video lessons were conducted on different studied topics, following the school curriculum ("Seasons and weather" - about the annual sequence of seasons, keeping the balance in nature, the four wonderful seasons and their peculiar weather; "Health is above wealth" - on the importance of health through the recitation of the human body parts, familiarization with the vocabulary to describe the well-being, how to promote health, training of verbal skills and interaction on this topic;. "What is Internet?" - Using the character John to introduce students to the concept of the Internet, the history of the Internet, its positive and negative impact on human life, etc.). When implementing the model of digital technology "Student-Internet-Teacher", for students (intermediate level of readiness), we proceeded from the interests of students, took 
into account the degree of language proficiency of students, and, if necessary, provided pedagogical support in the form of recommendations for independent work based on platforms: childrensbooksonline.org with scanned books and audiobooks Books with Audio for simultaneous reading, listening and repeating to practice correct pronunciation and understanding of the meaning of texts. They recommended using the childrensbooksonline.org platform, as it is convenient to bundle books by levels of difficulty from Pre-Reader to Adult-Readers, as well as to refer to the Equio service, which works equally well both in the browser version and in the mobile phone application.

Implementing the model of digital technology "Pupil - Internet - Center" and "Pupil Internet -... (several centers, several teachers)" for schoolchildren (high level of readiness) we used "Hypermedia" technology for tutoring, teaching support of schoolchildren with the dominant role of new information technologies, computer telecommunications, given the high independence of this group of students, we focused on finding additional opportunities to reveal their creative potential, implementation of their individual Thanks to the emergence of new digital learning technologies and online platforms: Skype, WhatsApp, Zoom, TrueConf, Discord, EDU (VGSPU platform), etc., providing video conferencing and streaming with a different number of participants (from 2 to 200), organization of text chats, publication of theoretical materials and tests, we are expanding new educational opportunities through the use of dynamically emerging new platforms and software products for distance learning, use the opportunity to access the ever-expanding array of information on the web. The increasing quantity and quality of communication for distance learning allow the teacher to provide pedagogical support to learners in their independent search for knowledge and guide them in comprehension and systematization. Conducting video lessons ("Phrasal verb "take" expanding students' understanding of the phrasal verb take, which is almost the most used and popular verb in English and the meanings it acquires in combination with various prepositions; activating its use in an oral and written speech of students with a detailed consideration and visual demonstration by examples, activating grammar practice, etc.) [12]. Conducting discussion platforms for a free exchange of opinions, development of the ability to defend one's position, self-expression in the context of foreign language speech: "Education. Career. Success" Discussion platform etc.

Using global web-based digital learning technologies, we do not exhaust the "what and how to teach" questions but search jointly with students for new solutions to the "how to learn" question through a combination of synchronous and asynchronous modes of distance learning as needed, switching from one to the other. Synchronous mode is used for student and teacher work in the same time parameters. The asynchronous mode is applicable in different situations. It provides freedom of choice for classes according to an individual curriculum using unified teaching materials for independent implementation of the individual trajectory of a pupil's educational route and development. For example, when the teacher and students discussed the topic (synchronous mode), we switched to exercises that the students did as homework at their convenience and sent to the teacher (asynchronous mode). Digital technology "videoconferencing" in distance learning is seen by students and teachers as the most convenient means for an effective learning process. Telecommunication provides "natural" audiovisual communication between the teacher and students of the virtual learning group using distance learning technology. All participants of the learning process see and hear each other, jointly consider and discuss various issues, events, videos.

Application of the above-described digital technologies based on models selected by us for different levels of student readiness is a dynamically developing set of full-time and distance learning resources, not opposing digital technologies of distance learning full-time, and performing a constant search for new information on electronic media by creating an information base together with students on the updated digital platforms, implementing personalized learning, promptly tracking 
At the end of May 2020, the repeated surveys were conducted, the analysis of the recordings of the video lessons conducted by the teachers of English and German (the number of the pupils present, their activity at the lessons, their interest in the lessons, the quality of the completed tasks), the conversations with the pupils and their parents were analyzed, and the obtained data were interpreted.

\section{Discussion of results}

The study presents the results of processed data obtained from official public sources and collected through own empirical data. For the first time, we received experimental material confirming the feasibility of using the described models of digital technology in modern schools in the experience of teaching a foreign language (following the identified levels of readiness of students). The transfer of schools to remote format to comply with measures to prevent the spread of coronavirus infection was accompanied by difficulties in organizing the educational process in remote mode (for students, teachers, parents of schoolchildren). We investigated one aspect in March-April 2020 - the readiness of students of educational institutions of Volgograd, studying a foreign language (only 23\% were ready, $61 \%$ of students had difficulties in online learning, and 38\% were not ready at all for technical, psychological and other reasons). Our preliminary assumptions about children's readiness for distance learning did not always coincide with the actual results obtained. For example, the pupils of MOU "School No. 3 of Traktorozavodsky district of Volgograd", Dima S. and Polina K., seriously engaged in "preliminary football training among 6-8-year-old boys and girls for sports schools admission" [20, p.733], we supposedly referred to a low level of readiness for distance learning in English, considering that they are too busy with their sports hobby. They are not particularly busy with their studies. But, to our joy, they became very organized and focused and managed to practice soccer independently and diligently study a foreign language and other subjects. Their level of preparedness proved to be high. However, Valentina N. and Artem B., pupils of MOU "School No. 19 of the Central district of Volgograd", having the most modern expensive tablets and phones, did not meet our expectations, and found only technical readiness, but did not show self-organization skills, self-control, independence in preparation for foreign language lessons; they were interested only in computer games "hurricane shooting", etc., so we referred them to the group of low readiness for distance learning.

School teachers, students - future teachers, during the periods of their pedagogical practice, under the guidance of the authors of this article, took part in the organization of the study. The results were obtained based on the questionnaire "My readiness for distance learning", analysis of video lessons conducted by English and German teachers (the number of students present, their activity at the lesson, their interest in the lessons, the quality of completed tasks), analysis of conversations with students and their parents. The experiment made it possible to apply digital technologies: "Single media" for pedagogical guidance of schoolchildren (low level of readiness), "Multimedia" for pedagogical support of schoolchildren (medium level of readiness), "Hypermedia" for pedagogical support of schoolchildren (high level of readiness). Digital technologies based on the described models, taking into account the levels of student readiness, helped them more quickly adapt to learning foreign languages in the new conditions (34\% became definitely ready, $63 \%$ had some difficulties with the overall readiness, $3 \%$ had difficulties with independence, coped only with the help of parents and friends); all participants in the experiment managed to get new achievements in personal growth and subject results in the foreign language, complete the school year, overcoming the difficulties of the new conditions digital 


\section{Conclusion}

The models of digital distance learning technologies described above represent separate educational directions and their dynamically developing unity. We have also recorded other combinations among the possible many others in the form of a dynamically developing aggregate of face-to-face and distance learning resources.

We do not oppose digital technologies of distance learning to face-to-face; it is complementary to the mainstream in some cases. In other cases, it is qualitatively new to the development of the future school. The search for new information in foreign language teaching is carried out on electronic media by creating an information base together with the learners. Digital platforms make it possible to increase interdisciplinary knowledge transfer efficiency, personalize a set of individual tasks for each student when learning a foreign language, and establish quick feedback. Automated testing of knowledge allows quick tracking the dynamics of changing perceptions, attitudes, and self-reflection of students: from a low level of readiness to intermediate and high. Distance learning contributes to students' independent "mining" of information and its understanding, the development of the ability to learn and withstand stress, to live in the digital world of the qualitatively new transforming school.

\section{References}

1. M.Yu. Gorbukha, Experience and prospects of teaching foreign languages in the Eurasian educational space 5, 787 (2020)

2. V.A. Kuklev, Formation of a mobile learning system in open distance education: author. dissertation of candidate of pedagogical sciences (2010)

3. O.P. Okolelov, Distance Education, 3, 37 (2000)

4. D. I. Saprykina, A. A. Volokhovich, Education Facts 4(29), 32 (2020)

5. T.M. Sklyarenko, Innovative projects and programs in education 2, 67 (2014)

6. V.I. Snegurova, Models of distance learning in the secondary education system https://cyberleninka.ru/article/n/modeli-distantsionnogo-obucheniya-v-sistemesrednego-obrazovaniya

7. O.S. Tarasenko, L.V. Burenko, Advanced Information Technologies and Intelligent Systems 2(30) (2007)

8. K.V. Tomilin, Open Distance Education 2(78), 45 (2020)

9. Federal Law of December 29, 2012 No. 273-F3 (as revised on July 31, 2020) "On Education in the Russian Federation" (as amended and supplemented, entered into force on August 1, 2020)

10. A.V. Khutorskoy, Researched in Russia 1-4, 5 (2000)

11. A.V. Khutorskoy, Modern didactics: textbook. for universities, 536 (2001)

12. I.V. Aleshchanova, N.A. Frolova, M.R. Zheltukhina, SHS Web Conf. 50, 01025 (2018a)

13. I.V. Aleshchanova, N.A. Frolova, M.R. Zheltukhina, ICTPPFMS 2018 198, 35 (2018b)

14. D. Coldeway, The American Journal of Distanse Education 2(3) (1988).

15. D.R. Garrison, M. Baynton, The American Journal of Distance Education, 1(3), 3 (1987)

16. D.R. Garrison, The International Review of Research in Open and Distance Learning, 1(1) (2000)

17. E. Meshcheryakova, J. Meshcheryakova. SHS Web of Conferences 69, 00077 (2019) 
18. E.V. Meshcheryakova, Y.V. Meshcheryakova, E.A. Loktyshina, BTCI 2018, 48(1), 12051 (2019)

19. M.G. Moore, M.M. Thompson, The Effects of Distance Learning: A Summary of Literature, Research Monograph Number 2, 83 (1990)

20. A.A. Suchilin, L.I. Stolyarchuk, I.N. Novokshchenov, Advances in Economics, Business and Management Research, 114 (2019)

21. J. R. Verduin, T.A. Clark, Distance Education: The Foundations of Effective Practice (1991) 